\title{
AS REDES IMPORTAM PARA O ACESSO A BENS E SERVIÇOS OBTIDOS FORA DE MERCADOS?
}

\section{Eduardo C. L. Marques}

Este artigo apresenta resultados de uma pesquisa recente sobre redes sociais de indivíduos pobres que habitam diferentes locais segregados em São Paulo. Redes sociais são representações analíticas dos contextos e dos padrões de relações que cercam uma dada situação social. No caso dessa pesquisa, trata-se dos padrões de relações ligados à sociabilidade cotidiana dos indivíduos. Foram pesquisadas as redes pessoais de 209 habitantes de sete locais de concentração de pobreza em São Paulo, submetidos a diferentes condições de segregação, além de trinta indivíduos de classe média. A pesquisa tinha por objetivo investigar, mediante análises quantitativas e qualitativas, as características das redes sociais de tais indivíduos, sua variabilidade e seus efeitos sobre a pobreza urbana. Esses efeitos foram avaliados por meio da análise das conseqüências das redes para o acesso a bens obtidos

Artigo recebido em dezembro/2008

Aprovado em agosto/2009 em mercados (Marques, 2008), como também a bens e serviços importantes para os processos de reprodução social dos indivíduos em situação de pobreza e obtidos por meio de ajudas e trocas sociais externas à lógica do mercado (Marques, no prelo).

Nesse artigo, discuto o papel das redes no acesso aos bens e serviços obtidos fora dos mercados. As informações utilizadas aqui são originárias de entrevistas em profundidades realizadas com vinte dos entrevistados anteriores que contavam com redes e sociabilidades de diferentes tipos. Apresentei aos entrevistados as redes previamente construídas, solicitando que discutissem sua mobilização na obtenção de ajudas variadas em suas atividades cotidianas. Foram feitas perguntas ligadas à migração, inclusive intra-urbana, à construção da habitação ou a pequenos reparos, aos cuidados com crianças e com a casa, a problemas de saúde, a empréstimos de mantimentos e dinheiro, a confidências e 
apoio emocional, à obtenção de cônjuge, de emprego e de informações sobre política, serviços e políticas públicas.

Inicio este artigo estabelecendo alguns pontos de partida conceituais necessários para a construção do argumento. Em seguida, descrevo os principais procedimentos de pesquisa adotados e resumo os resultados anteriores. A terceira seção discute os tipos de ajuda disponibilizados pelos indivíduos, destacando a sua relação com as redes. Os resultados evidenciam a existência de padrões na mobilização das redes pelos indivíduos para a obtenção de ajudas. A estrutura do texto segue esses padrões, utilizando sempre nomes fictícios para os entrevistados. Ao final, sintetizo os principais padrões encontrados à guisa de conclusão.

\section{Trocas, ajudas e confiança}

Nesta seção defino conceitualmente os principais elementos envolvidos nessas relações de aju$\mathrm{da}$ - as trocas, a confiança, a reciprocidade e a intimidade. Não se trata de desenvolver uma discussão conceitual detalhada dessas categorias nas ciências sociais, ou de discutir demoradamente os tipos de relações existentes em dadas situações sociais, como faz Blokland (2003), mas de estabelecer os pontos de partida conceituais necessários para o entendimento da análise que se segue. Por outro lado, a pesquisa não objetivou alcançar categorias nativas, mas analisar esses importantes processos levando em conta as interpretações dos entrevistados, sem a pretensão de reproduzi-las.

As ajudas analisadas aqui importam em trocas. Essas trocas são todas intrinsecamente sociais (Polanyi, 1980) e envolvem o intercâmbio de elementos materiais e imateriais, mas também dimensões simbólicas. As ajudas e o apoio social envolvem trocas, pois estão submetidas às lógicas da reciprocidade como as estudadas originalmente por Mauss. No sentido destacado pela tradição antropológica do dom, os elementos envolvidos na troca conformam conjuntos de sentido social e simbólico abrangente que, em sua formulação original, forneceram chaves interpretativas para elementos societários amplos (Mauss, [1923] 2003) e tem sido aplicada desde então a diversas dimensões sociais (Lanna, 1995; Vilela, 2001).

Em um sentido mais específico, as trocas diferem entre si com relação ao seu caráter mais ou menos impessoal em um contínuo, desde trocas generalizadas ou impessoais até as mais personalizadas ou específicas (Nunes, 1997), nas quais os atributos dos envolvidos na transação importam. As trocas mercantis, que podem ser mediadas pelo dinheiro ou ocorrer em espécie, são as mais intensamente impessoais, embora saibamos que sempre envolvem relações sociais e, conseqüentemente, são mediadas por diversos processos sociais, materiais e simbólicos (Weber, [1922] 1999; Polanyi, 1980). É razoável imaginar que em contextos de pobreza, em que diversos tipos de informalidade estão presentes nas trocas mercantis, o grau de impessoalidade seja menor. Nesse caso, as trocas da economia estão mais atravessadas pela economia das trocas. ${ }^{1}$

Uma grande parte das condições de vida na cidade envolve trocas mercantis, o que tem como conseqüência óbvia que indivíduos de menor renda (e pior inseridos no mercado de trabalho) encontrem maiores dificuldades de obter e manter boas condições sociais. A relação entre as redes e os elementos que medeiam as trocas mercantis (renda e trabalho, principalmente) foi analisada em outros trabalhos (Marques, 2008; no prelo) e não serão discutidas aqui. As demais trocas que envolvem ajudas, entretanto, podem melhorar as condições de vida e solucionar problemas cotidianos de indivíduos com baixíssimo acesso à renda, que não dispõem de recursos econômicos para comprar bens e serviços via mercado.

Nessas trocas são intercambiados bens materiais, como dinheiro, mantimentos, ferramentas, entre outros, mas também elementos imateriais, como informações, afetos, solidariedade, apoio emocional etc. Além disso, todas essas trocas também envolvem dimensões marcadamente simbólicas, como reconhecimento e prestígio. Elas nem sempre envolvem bens similares, e tampouco ocorrem de forma imediata, construindo condições de dívida inseridas na lógica da reciprocidade social. Em alguma medida, padrões relacionais são sempre redes de trocas, não apenas pelo que pode fluir pelas relações, mas também pela reciprocidade envolvida 
e pelos graus de confiança e intimidade que as viabilizam e perpetuam no tempo. Os tipos das próprias relações, adicionalmente, podem ser transformados de acordo com as dinâmicas das trocas, a reciprocidade e confiança envolvidas, como será apontado mais adiante.

Por outro lado, todos os tipos de ajuda envolvem também custos de várias naturezas. Esses custos incluem recursos materiais como dinheiro e bens, mas também tempo despendido no auxílio, assim como investimentos operacionais e emocionais de quem ajuda. Evidentemente, os custos nessas práticas são mediados pelas condições de reciprocidade existentes e podem ser mitigados, em parte, pelos tipos de vínculo envolvidos. Nesse sentido, quanto mais custosa for a ajuda prestada, mais ela dependerá da existência de certos tipos de vínculo e da confiança na relação que medeia a reciprocidade (tornando mais ou menos confiável esperar a retribuição futura). Como comentarei mais adiante, entretanto, a presença de reciprocidade social e de confiança não afastam necessariamente a presença de monetarizações nas ajudas.

Por confiança entendo a segurança no cumprimento das expectativas de uma dada relação, quaisquer que sejam tais expectativas. Para alguns entrevistados, confiança depende de homofilia ${ }^{2}$ confia-se em quem tem atributos (ou comportamentos) similares. Para outros, há tipos distintos de confiança, associados a situações sociais específicas. A análise dos casos sugeriu que, dependendo da situação, há expectativas diferentes regulando as relações e estabelecendo tipos diferentes de confiança. Foram observados ao menos três tipos de confiança - pessoal, profissional e política/associativa.

A primeira é a mais comum e diz respeito à segurança do ego em relação a seus contatos no que concerne a assuntos de natureza pessoal. Ela se associa à intimidade, mas só depende dela nas relações de confidência, como veremos a seguir. A confiança profissional diz respeito à segurança que um determinado ego tem de que seus contatos vão cumprir as regras pactuadas em atividades profissionais. Esse tipo de confiança apareceu em entrevistas com proprietários de pequenos negócios e com outros que contam com parceiros regulares de trabalho. Por fim, a confiança política/associativa é a que apareceu com menor freqüência. Refere-se à segurança de que seus companheiros cumprirão os pactos estabelecidos no desenvolvimento de atividades e no estabelecimento de alianças e disputas políticas. Em todos esses casos, confiança pode estar presente tanto em relações horizontais como em verticais, sendo compatível com desigualdades de poder e hierarquias.

Graus diferentes de confiança, por seu turno, associam-se usualmente a formas diversas de reciprocidade. Na maior parte das vezes, ajudas com baixa confiança estão associadas à reciprocidade moral e impessoal típica do pertencimento a grupos, como no que Blokland (2003) denomina attachments seguindo Weber ([1922] 1999) - relações não instrumentais, mas baseadas na racionalidade e em valores de pertencimento a grupos circunscritos por identidades compartilhadas. Relações também mobilizadas pela reciprocidade que envolve permuta direta e tem dimensão mais instrumental, que Luciano, um entrevistado da favela do Jaguaré, chamou de "toma-lá-dá-cá". Enquanto as relações que veiculam as primeiras estão associadas tanto à racionalidade (ação deliberada e consciente) como a valores, as segundas baseiam-se em ações racionais e orientadas a fins de maneira similar ao definido por Blokland (2003), seguindo Weber ([1922] 1999). No outro lado do espectro, as relações que envolvem alta confiança associam-se a trocas específicas e a reciprocidades que podem se distribuir no tempo e envolver diferentes bens materiais e imateriais. Nesse caso, a reciprocidade é inteiramente personalizada e garantida por um tipo específico de vínculo pessoal.

Intimidade, por outro lado, também diz respeito à segurança do cumprimento das regras das relações, mas é especializada em assuntos pessoais que envolvem sigilo e depende de graus mais elevados de confiança. Nas palavras de João, morador de um conjunto habitacional na Cidade Tiradentes, “intimidade é jogo aberto". Diferentemente de confiança, intimidade aparece apenas em relações com pequenas diferenças hierárquicas e de poder.

Além dos custos diferenciados das ajudas, variações nos tipos de vínculos e nos graus de confiança presentes nas relações, portanto, influenciam os auxílios disponíveis e podem impactar sobremaneira as condições de vida e a pobreza. 


\section{Desenho da pesquisa e resultados anteriores}

O estudo levantou as redes pessoais de 209 indivíduos em situação de pobreza e trinta indivíduos de classe média, de forma a construir um padrão de comparação. De maneira a explorar os efeitos da segregação espacial sobre as redes pessoais, escolhi sete locais bastante distintos sob o ponto de vista da distância ao centro, dos graus de consolidação das áreas, dos padrões construtivos e dos graus de intervenção do Estado, partindo de estudos anteriores sobre pobreza em São Paulo (CEM/SAS 2004). Optei por analisar redes pessoais, e não redes de comunidades ou redes centradas em indivíduos, ${ }^{3}$ pois considero que uma parcela importante da sociabilidade que influencia a pobreza ocorre a distâncias maiores do ego do que o seu entorno imediato. ${ }^{4}$

Foram realizadas trinta entrevistas por local entre setembro de 2006 e agosto de 2007, incluindo cortiços centrais, quatro favelas - Vila Nova Jaguaré, Paraisópolis, Vila Nova Esperança e Guinle-, um loteamento irregular no Jardim Ângela e o conjunto habitacional de Cidade Tiradentes, além do grupo de controle de classe média, sem especificação de local de moradia. $\mathrm{Na}$ verdade, a localização da classe média indica um padrão concentrado no centro expandido da metrópole, embora suas redes se expandam por um amplo território e não incluam vizinhos, em um padrão similar ao que Wellman (2001) denomina "comunidades pessoais".

As entrevistas utilizaram um questionário semiaberto e um gerador de nomes e foram escolhidas ao acaso ao longo de percursos pelos locais estudados, tanto em dias de semana como durante fins de semana. ${ }^{5}$ A classe média foi definida de maneira ampla, uma vez que visava apenas a constituir um padrão de comparação para a análise das demais redes.

Essas informações foram tratadas com ferramentas de análise de redes sociais, resultando em 239 redes pessoais. ${ }^{6}$ Após a realização das análises estatísticas, escolhi intencionalmente um conjunto de vinte redes pessoais para empreender a parte qualitativa da pesquisa, combinando tipos de redes, locais e características dos entrevistados. ${ }^{7}$ O presente artigo explora essas informações qualitativas, desvendando os padrões associados às redes e à sociabilidade que medeiam o acesso dos indivíduos a bens e serviços obtidos fora de mercados.

Antes de avançarmos, entretanto, apresento de forma resumida os principais resultados das etapas anteriores da pesquisa, de forma a melhor situar o leitor.

Em primeiro lugar, é preciso registrar que quando comparadas com as redes de classe média, as redes pessoais de indivíduos pobres tendem a ser menores, mais locais e menos variadas em termos de sociabilidade. Praticamente inexistem relações entre grupos sociais e de renda. Essa é uma das mais importantes características dessas redes para a reprodução da pobreza e da desigualdade social que, entretanto, não se origina nas redes, mas representa apenas uma faceta relacional da estrutura social.

Os sociogramas a seguir apresentam como ilustração as redes de duas mulheres, uma pobre e outra de classe média, com características próximas das médias de cada grupo. Sociogramas são representações gráficas dos padrões de vínculo, nas quais entidades (pessoas, grupos, empresas, organizações) são representadas como pontos (os nós) e relações (de qualquer tipo) como traços (os vínculos). Como se pode observar, a primeira rede é menor, mais simples, menos "clusterizada" e mais centralizada no ego do que a segunda.

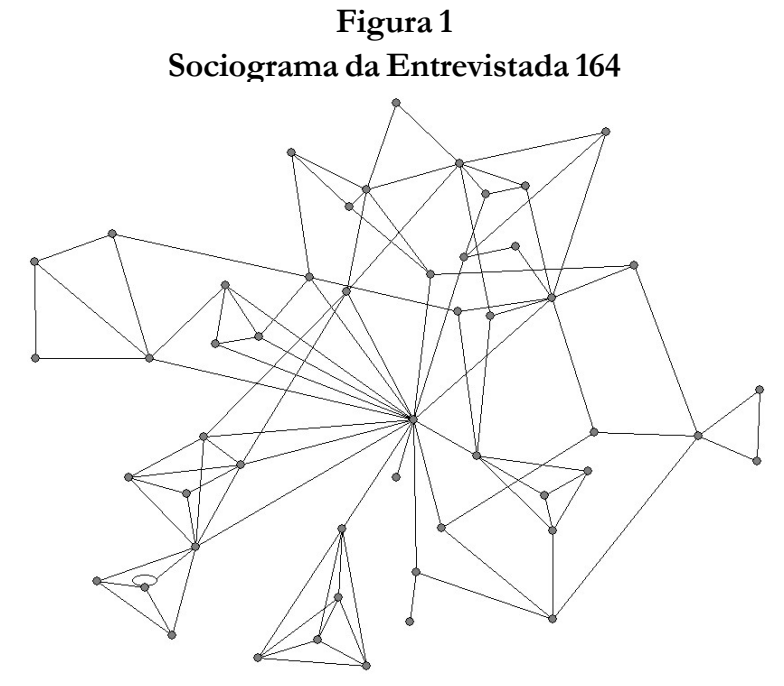

Fonte: Elaboração própria a partir de material empírico coletado. 
Figura 2

Sociograma da Entrevistada 93

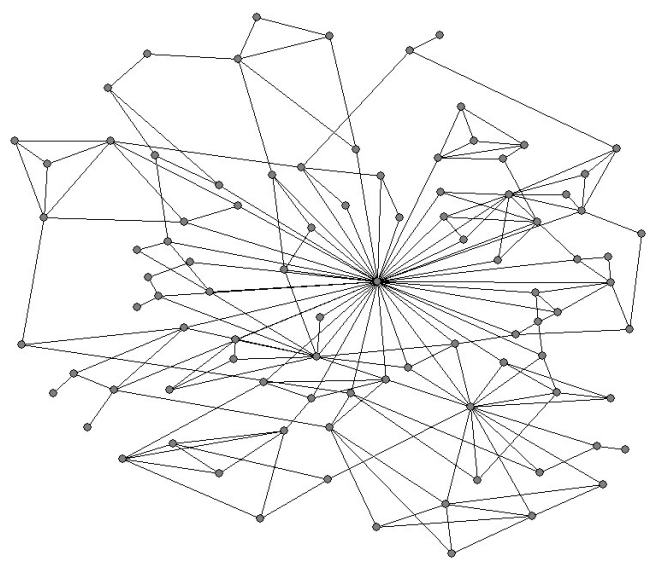

Fonte: Elaboração própria a partir de material empírico coletado.

Apesar disso, as redes de cada grupo variam substancialmente entre si. Os sociogramas a seguir apresentam também como ilustração as redes de dois indivíduos pobres com padrões relacionais polares. Nas Figuras 3 e 4, a simbologia dos nós indica as esferas de sociabilidade onde ocorre o encontro entre o ego e cada indivíduo.

Figura 3

\section{Sociograma do Entrevistado 155}

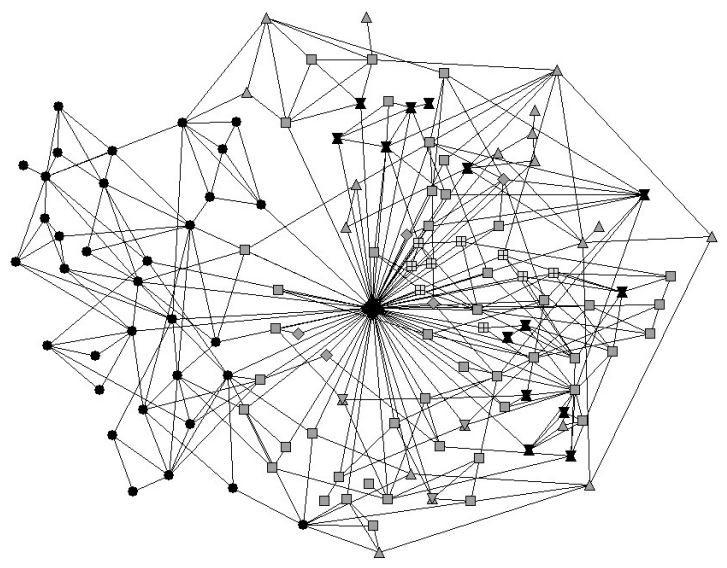

Nota: Esferas de sociabilidade: losango grande - ego; círculos pretos - família; quadrados - vizinhança; triângulos - amizade; quadrados claros com sinal de mais - estudos; ampulhetas pretas - lazer; losangos escuros - outros.

Fonte: Elaboração própria a partir de material empírico coletado.
Figura 4

Sociograma da Entrevistada 142

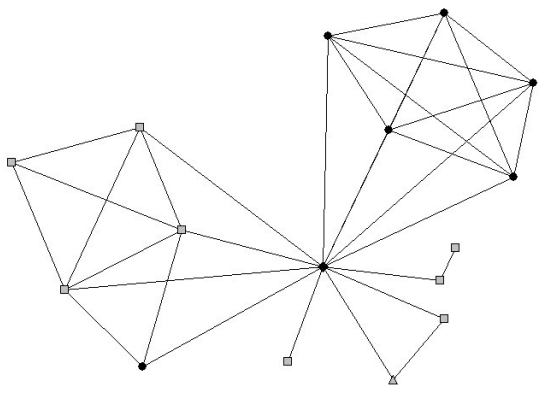

Nota: Esferas de sociabilidade: losango preto - ego; círculos pretos - família; quadrados - vizinhança; triângulo - amizade. Fonte: Elaboração própria a partir de material empírico coletado.

A análise indicou não existirem relações diretas entre variáveis socioeconômicas e padrões de relação. $\mathrm{Na}$ verdade, as redes são influenciadas por diversos condicionantes socioeconômicos, como sexo, idade, escolaridade, renda, migração, freqüência, templos, associações e a própria segregação. ${ }^{8} \mathrm{O}$ efeito desses condicionantes tende a circularidades que perpetuam as situações sociais e relacionais e reproduzem desigualdades de forma persistente, embora não necessariamente desigualdades categoriais no sentido de Tilly (2005). ${ }^{?}$

Considerando a variabilidade encontrada nas redes, construí duas tipologias - das redes e dos padrões de sociabilidade. Os achados indicaram que, embora as redes de indivíduos pobres sejam em geral menores, mais locais e menos variadas do que os de indivíduos de classe média, também variam muito. Se, de um lado, estão presentes padrões de sociabilidade muito locais e baseados em vínculos primários (família, vizinhança e amizades), de outro, uma parte significativa dessas redes apresenta sociabilidade pouco local e produzida em ambientes organizacionais ou institucionais (trabalho, igreja, associativismo). O cruzamento dessas heterogeneidades sugeriu a existência de padrões relacionais amplos, com sociabilidade variada e homofilia potencialmente menor.

A análise a seguir especificou os impactos das redes sobre as condições sociais, em especial sobre a pobreza. Ficou evidenciado que o emprego, 
inclusive o com maior proteção, e a ausência de precariedade social tendem a ser influenciados positivamente por padrões de sociabilidade pouco locais e primários, ao contrário de variáveis tradicionais, como escolaridade, idade e renda, que não se mostraram significativas. Além disso, as redes e o tipo de sociabilidade ajudaram a explicar o rendimento dos indivíduos, em conjunto com variáveis tradicionais. Os resultados de análise multivariada mostraram a significância, entre as variáveis tradicionais, do tamanho do domićlío e da escolaridade dos indivíduos. Além disso, entretanto, três outras variáveis associadas às redes também se mostraram relevantes - o tipo de rede e de sociabilidade (redes médias e variadas e com sociabilidade pouco local e pouco primária), o tamanho das redes e a variabilidade da sociabilidade, essas duas últimas em interação respectivamente com ter rendimento estável e ser segregado. Redes médias e com sociabilidade pouco local e primária, portanto, geram efeitos positivos sobre a renda (Marques, 2009; no prelo). No caso de alguns indivíduos segregados, esse efeito é potencializado pela presença de sociabilidade variada, ajudando a combater o isolamento social produzido pela segregação.

Entretanto, restava compreender melhor a mobilização cotidiana das redes pelos indivíduos. A seção que se segue, baseada no material qualitativo da pesquisa, avança nessa direção explorando o uso e a mediação da sociabilidade e das redes no acesso dos indivíduos a bens e serviços obtidos fora de mercados.

\section{Acessos e ajudas}

As informações das entrevistas sugerem que as ajudas que medeiam os acessos podem ser agrupadas segundo um cruzamento entre graus de confiança, custos e tipos de reciprocidade. Dependendo da situação, a reciprocidade e a confiança envolvidas ganham vários contornos e feitos, e a troca em si pode ser mais ou menos personalizada. Por outro lado, no contexto específico da reciprocidade de cada ajuda, os custos, que evidentemente não se restringem a dimensões monetárias, ganham conteúdos distintos, misturando por vezes prestígio, afeto, expectativa de retribuição e dinheiro. Outra dimensão relevante desses custos é o tempo e a disponibilidade pessoal gastos na ajuda, assim como sua freqüência e perenidade. Assim, embora no mundo dos pobres circule relativamente pouca riqueza, são bastante freqüentes ajudas de custo elevado.

Por vezes é tênue o limite entre o que é inteiramente compra via mercado e o que é troca mediada pela reciprocidade social, mas que também envolve pagamento em dinheiro. No primeiro caso, apesar de os indivíduos serem conhecidos, trata-se da compra de um serviço que poderia ser adquirido de outro prestador. Por outro lado, há ajudas que também podem envolver pagamento em dinheiro, mesmo para pessoas muito próximas. Nesse caso, o dinheiro é apenas uma das dimensões envolvidas na troca, que não é generalizada, mas específica e personalizada pela confiança envolvida. Aparentemente, os pagamentos representam retribuições que contribuem para reduzir os custos das ajudas, assim como elementos como prestígio, afetos e outros auxílios prestados ou devidos para prestação em momento futuro, no contexto da reciprocidade.

Considerando essas dimensões, são basicamente três os tipos de ajuda observados: imediatas e com baixo custo, mais constantes e custosas, e que envolvem confiança e intimidade. Discuto a seguir com algum grau de detalhe esses tipos, trazendo exemplos dos entrevistados sempre que possível. De uma forma geral, do primeiro ao último tipo crescem continuamente a confiança na relação necessária para a ajuda e os custos envolvidos na sua prestação. Ao mesmo tempo, cada ajuda associa-se a um tipo específico de reciprocidade.

\section{Ajudas mais imediatas e de baixo custo e que necessitam de baixa confiança}

Este tipo envolve auxílio durante crises agudas de saúde, empréstimo de ferramentas e de mantimentos, olhar a casa durante a ausência dos donos, assim como informações para emprego e a respeito de políticas e serviços públicos.

É também ligado muito freqüentemente por vínculos fracos e freqüentes, mas superficiais, 
definidos por Luciano, morador da favela Jaguaré, como "oi, oi, tudo bem?". Em geral, trata-se de uma forma de ajuda que ocorre por relações muito pouco personalizadas e com reciprocidade bastante distante. Grande parte dos vínculos que a carreiam é originária da vizinhança e tende a se quebrar facilmente, em especial com o deslocamento da residência. Esses vínculos, entretanto, são substituídos de forma relativamente fácil no novo local de moradia, embora alguns lugares possam ser considerados melhores do que outros pelos entrevistados nesse sentido. Os laços que fomentam esse tipo de ajuda se comportam como se correspondessem a suportes impessoais de relações de reciprocidade de ajuda cotidiana. Nesse caso, não é necessário a confiança e a reciprocidade é tênue.

O que embasa esse tipo de ajuda é um sentimento de solidariedade difusa. Se considerarmos que todos os tipos de solidariedade estão associados a identidades, nesse caso se trata de uma identidade difusa ou de pertencimento a grupos amplos, como "nós da comunidade", "os pobres", "os irmãos" ou mesmo "os seres humanos". O discurso dos entrevistados para justificar ajudas desse tipo é associado ao pertencimento a esses grupos ou a solidariedades amplas, como para João, morador de um conjunto habitacional na Cidade Tiradentes, que sustenta que de "pessoa doente, até os inimigos se compadecem". As crises agudas de saúde exemplificam tais situações, onde é freqüente a ajuda de vizinhos, em especial emprestando carros e conduzindo o paciente até unidades de saúde, como em situações relatadas por Lúcia, David, Luciano e Rafaela, moradores de cortiços e das favelas de Paraisópolis, do Jaguaré e da Vila Nova Esperança, respectivamente. Os tipos de relação que veiculam essa ajuda são principalmente o que Blokland (2003) denomina de attachments.

Mesmo que esse tipo de ajuda não necessite de confiança prévia, ela pode ser negada pela quebra no passado da reciprocidade mínima esperada, tanto de forma personalizada, como generalizada. Nas palavras de João, de Tiradentes, "ferramenta eu sempre emprestei muito, mas hoje não empresto mais, pois as pessoas não devolviam". De maneira inversa, a prestação de auxílio no caso de doença pode levar a um aprofundamento da relação entre indivíduos, aumentando a confiança na pessoa que ajudou e levando mesmo a um grau mais elevado de intimidade. Assim, embora nem confiança nem intimidade sejam necessárias para que um indivíduo preste esse tipo de ajuda, dado o seu caráter quase impessoal, tanto a confiança como a intimidade podem ser impactadas pela prestação desses auxílios, positiva ou negativamente.

O fornecimento de informações a respeito de emprego pode se associar a todos os tipos de ajuda, mas também pode ser veiculado pelos laços que carreiam as ajudas imediatas e de baixo custo, em especial para os empregos mais locais. Em sua forma mais extrema, a informação pode vir até de desconhecidos. No caso de João, por exemplo, a informação que o levou a um emprego foi dada por um desconhecido em uma praça, e para Ednalva, da favela de Paraisópolis, foi obtida de uma pessoa que conheceu no ônibus. Maria, desempregada e moradora da favela do Jaguaré, que sobrevive catando papéis, obteve um emprego como empregada doméstica por intermédio de uma pessoa que conheceu quando passou a freqüentar uma igreja. O fornecimento dessas informações tem baixíssimo custo e é propagado por contatos muito pouco intensos e, por vezes, quase ao acaso, de forma similar aos vínculos fracos de que fala Granovetter (1973).

A esse respeito especificamente, alguns locais onde informações circulam mais intensamente parecem gerar contatos potenciais com redes de outros indivíduos que se conhecem pouco, ou até mesmo com desconhecidos. Nesse caso, não se trata de um efeito da rede de um dado ego, mas de espaços de convívio específicos que dão acesso a redes de outros indivíduos que podem nem mesmo participar da sua rede. Esse é o caso do salão de cabeleireiro de Antônio, também pastor e diretor de uma organização comunitária em Paraisópolis. Segundo as entrevistas, aquele espaço representa um importante local de troca de informações, para o qual os indivíduos convergem. Às vezes isso também ocorre em torno de certos indivíduos, que, como se sabe, têm muitos contatos. Rafaela, de Vila Nova Esperança, e Antônio e Jorge, de Paraisópolis, por exemplo, afirmaram serem procurados com freqüência, inclusive por desconhecidos, para perguntar se sabem 
de ofertas de emprego. Não por acaso, esses três indivíduos são lideranças em seus bairros e estão envolvidos com atividades associativas.

Entretanto, é importante reportar uma diferença com relação aos resultados do influente trabalho de Granovetter. O argumento do autor a respeito da força dos vínculos fracos na busca de emprego baseia-se na idéia de que, se um dado ego se encontra desempregado há algum tempo, o emprego não chegará a ele por vínculos fortes, caso contrário ele já estaria empregado. Tecnicamente o argumento diz respeito a uma regularidade empírica observada por Granovetter e batizada por ele de "tríade aberta proibida": se um determinado ego tem uma relação forte com A e outra com B, é muito pouco provável que A e B não tenham relação. Por isso, informação nova não chegaria aos indivíduos por vínculos fortes, mas por vínculos fracos. ${ }^{10}$

Em uma aparente contradição com os achados de Granovetter, uma parte importante dos empregos de melhor qualidade encontrados veio de vínculos fortes, inclusive da família. Entretanto, a evidência diz respeito em especial aos primeiros empregos de indivíduos recém-migrados ou que ingressam no mercado de trabalho pela primeira vez. A questão está em que, quando ocorrem os primeiros contatos dos indivíduos com as redes que os acolhem (ou que os integram ao mercado, no caso dos adolescentes que começam a trabalhar), informações novas sobre emprego chegam tanto por vínculos fortes como por vínculos fracos. ${ }^{11}$ Esse efeito tende a ser ainda mais forte para indivíduos de baixa qualificação e que se encontram no limite da sobrevivência, para quem virtualmente qualquer ocupação pode fazer diferença.

Fazem parte dessa situação os casos de Ana Luiza, Luciano, João, Rafaela, Lúcia e David, para quem empregos importantes em suas trajetórias vieram de informações trazidas por familiares. No caso dos quatro primeiros, os empregos foram obtidos quando chegaram a São Paulo do Nordeste, mas os casos de David e Lúcia envolvem jovens que iniciaram suas vidas profissionais no final da adolescência já em São Paulo.

Apesar desse ponto em comum, as trajetórias (e suas conseqüências) são muito diferentes. Ana Luíza obteve um emprego estável em uma loja de roupas para noivas no centro de São Paulo por meio de um parente, mas planejou se transformar em autônoma. Depois de um período no trabalho, aprendeu a fazer grinaldas com ajuda de colegas e pediu as contas. Desde então, produz em casa, utilizando os contatos que construiu na loja. Obtém um rendimento mais alto, além de ter controle sobre o processo de trabalho e não precisar se deslocar diariamente de Vila Nova Esperança até o Centro. O caso de Luciano também merece menção. Após trabalhar junto com os irmãos em uma padaria de um bairro de classe média próximo à Vila Nova Jaguaré, também iniciou um negócio próprio. Após um período de crise, quando teve que contrair empréstimos de alto valor e vender sua casa para pagar dívidas, tem hoje uma situação bastante próspera em termos relativos. João, de Tiradentes, também obteve o seu primeiro emprego em São Paulo por intermédio de um cunhado em uma marcenaria, embora sua trajetória posterior seja muito menos bem-sucedida do que as de Ana Luíza e Luciano. Por fim, Rafaela, da Vila Nova Esperança, foi ajudada pela tia em dois momentos sucessivos. Em seu primeiro emprego em São Paulo; após um ano ela voltou para o Nordeste, e quando retornou da migração pendular foi novamente a tia que lhe conseguiu um emprego.

O efeito no caso de jovens paulistanos que obtêm os primeiros empregos é similar. David brigou com o pai no final da adolescência e saiu de sua casa em Paraisópolis, obtendo seu primeiro emprego em uma loja de fotografia conseguido por uma irmã. E os filhos de Lúcia conseguiram seus primeiros empregos com um tio, em uma borracharia em um bairro próximo à Vila Nova Esperança.

Os dois primeiros casos - de Ana Luíza e Luciano - ainda sugerem que o planejamento de futuro também pode cumprir um papel bastante importante para o aproveitamento das oportunidades relacionais que chegam até os indivíduos. A presença ou não desse planejamento está associada aos enquadramentos culturais por meio dos quais os indivíduos vêem a sociedade e suas situações, no sentido de Lamont e Small (2008, p. 8): “um esquema interpretativo que simplifica e condensa a realidade social, escolhendo e codificando seletivamente objetos, situações, eventos, experiências e seqüências de 
ações". Em ambos os casos reportados acima, dadas as condições diante frente das quais foram colocados, os entrevistados planejaram sua inserção, o que lhes permitiu utilizar o conhecimento que haviam obtido na padaria e na loja de artigos para noivas para iniciarem seus negócios como proprietário e como autônoma, respectivamente.

No outro extremo, localizam-se pessoas que apresentam uma postura mais passiva com relação à sua trajetória. A situação pode ser ilustrada pelas palavras de João, de Tiradentes, que teve longas e importantes relações com indivíduos sem atividade profissional e que faziam muito pouco esforço para melhorar sua situação. Nas suas palavras, seu companheiro por nove anos "não lutava". Para ele, muitas pessoas "não têm ambição, talvez seja comodismo ou preguiça. Falo de ambição normal, de ter uma casa, com as minhas coisinhas no armário". A questão, entretanto, não está relacionada apenas com esforço, mas com planejamento: essas pessoas "só se lembram de comer quando tão com fome. Não dá assim. Só lembrar de plantar quando tá com fome". Acredito que esse comportamento pode ser pensado não apenas como produto de escolhas, mas também como um resultado adaptativo à cumulatividade de precariedades ocorridas ao longo da trajetória de certos indivíduos, reduzindo os seus graus de liberdade.

Vale acrescentar um último ponto relativo aos auxílios para acessar serviços e políticas estatais. As informações não sugerem a existência de ajuda personalizada envolvendo reciprocidade eleitoral na obtenção de serviços e políticas públicas, ao contrário do que sustenta uma vasta literatura sobre clientelismo político. Confirmando resultados de pesquisas anteriores sobre acesso a políticas e serviços em São Paulo (Figueiredo, Torres e Bichir, 2006), não foi encontrada intermediação pessoal, política ou qualquer outra associada a relações de reciprocidade eleitoral na busca desses tipos de serviço.

Essa tendência liga-se à universalização do acesso às políticas e aos serviços mais básicos, já demonstrada por pesquisas específicas sobre o tema (Figueiredo, Torres e Bichir, 2006; Figueiredo et al., 2005, por exemplo). Entretanto, ela não significa a inexistência de trocas sociais associadas a acessos, mas indica, em contrapartida, o estabelecimento de patamares mínimos de direitos, retirando destes o caráter de moeda negociável eleitoralmente. Essa distinção é importante conceitualmente, pois a tradição de estudos nesta área considera o clientelismo político se faz presente quando os acessos envolvem trocas de alguma forma. Como sabemos, as relações sociais são em si trocas, o que torna ingênua a interpretação da institucionalização das políticas públicas como um processo de desimbricação social das relações entre Estado e sociedade. Basta que pensemos em todas as dimensões sociais envolvidas na implementação das políticas pela burocracia de nível da rua indicadas por Lipsky (1980). ${ }^{12}$

A questão incide sobre o que circula nas trocas associadas aos acessos a políticas, e não no caráter mais ou menos "desencarnado" socialmente dessas trocas. O clientelismo caracteriza-se pelo estabelecimento de relações onde a ajuda no acesso a políticas é trocado por apoio eleitoral. É essa dimensão que sofre impacto pela expansão universalista das políticas públicas, visto que o valor eleitoral dos apoios cai a níveis muito baixos se as políticas são entendidas e - muito mais importante, sentidas como direitos.

Assim, apesar de não existirem trocas políticoeleitorais no sentido clássico, apareceram com alguma freqüência encaminhamentos institucionais que têm muitas vezes caráter pessoal, como a diretora da escola de Carlos, um jovem morador de cortiços, que o encaminhou e conseguiu vaga em outra escola. Esse também foi o caso de Marta, outra moradora de cortiços, que conseguiu vaga em um curso de informática por intermédio da diretora da creche municipal onde estuda seu filho. Nessa mesma direção, técnicos de uma política podem cumprir funções importantes em outras iniciativas públicas, explicando procedimentos e encaminhando para atendimento, como no caso do papel de mediadores exercido pelos agentes comunitários de saúde (Lotta, 2006). Além disso, contatos nas redes e nas associações comunitárias também veiculam esse tipo de ajuda, em especial em redes de indivíduos muito pobres ou idosos. Em um dos locais estudados, o padre da diocese local, por exemplo, que exerce uma poderosa liderança social e política, ocupa esse papel de mediador entre a esfera local e o universo formal das instituições. 
Como essas trocas envolvem reciprocidade, os indivíduos que produzem tal mediação freqüentemente ganham projeção e distinção, especialmente entre os mais pobres e idosos, que dependem mais desse tipo de apoio. Entretanto, em todos esses casos, trata-se mais da disponibilização de informações e da ajuda no preenchimento de formalidades (que comumente apresentam grande dificuldade para esse grupo social) do que de intermediação no sentido clássico da expressão, associado a formas de reciprocidade envolvendo retornos eleitorais.

\section{Ajudas mais constantes ou crônicas e custosas}

Esse tipo de ajuda envolve situações crônicas de saúde que demandam atenção constante, cuidados cotidianos com crianças, obras na casa, ajuda na migração e empréstimos de pequena monta. Em todos esses casos, trata-se de atividade relativamente custosa (embora não necessariamente financeiramente) para quem ajuda. Os casos estudados indicam que freqüentemente há remuneração, mesmo para pessoas muito próximas (irmãos, mãe, amigos íntimos etc.). Interpreto esses pagamentos como uma tentativa de reduzir os custos envolvidos para quem ajuda, mas isso não deve ser considerado uma característica de uma relação mercantil corriqueira, pois aqui a troca envolve reciprocidade e depende de confiança. Nesse sentido, a prestação desses auxúlios de forma inteiramente mercantil e despersonalizada não representa ajuda no sentido empregado estamos empregando. No caso da classe média, ajudas custosas desse tipo são freqüentemente contratadas no mercado, tais como creches, babás, enfermeiras, pedreiros e empréstimos no banco. No caso dos pobres, entretanto, a contratação via mercado se resume aos serviços especializados de construção. Os demais auxílios desse tipo são prestados socialmente e estão sujeitos às lógicas da reciprocidade e da confiança.

Os cuidados com crianças enquanto os pais trabalham são usualmente prestados por familiares, inclusive irmãos mais velhos ou vizinhos, com ou sem pagamento em dinheiro. No caso de Jorge, morador de Paraisópolis, a tarefa sempre foi paga para uma cunhada, e de Maria, moradora da área mais pobre do Jaguaré, vizinhos cuidavam das crianças, também mediante pagamento. Maria chegou a afirmar que "ninguém faz isso de graça". Jorge e sua mulher nunca precisaram que alguém cuidasse cotidianamente das crianças, mas sua cunhada leva as crianças para a escola e recebe uma pequena remuneração mensal. Por outro lado, em alguns casos foram relatadas ajudas não remuneradas de vizinhos, embora sejam relativamente freqüentes relatos de maus-tratos. Por essa razão, a confiança é indicada como uma dimensão importante dessa tipo de auxílio, embora nem sempre os indivíduos contem com pessoas de confiança para assumir a tarefa.

Cuidados com doente crônicos também envolvem elevados custos e necessitam de confiança. O mesmo se pode dizer do auxílio cotidiano às mulheres que acabaram de dar à luz. Nesses casos, quase sempre é a família que presta apoio. Quando a parturiente mora longe da família e não conta com uma rede de apoio de vizinhança forte, tende a se deslocar provisoriamente para junto da família, mesmo que para condições habitacionais muito piores. Em um caso reportado por Carlos, sua irmã, que mora fora de cortiço em casa própria de boas condições, mudou-se durante o final da gravidez, que era de risco, para o quarto no cortiço onde moram o entrevistado, seu irmão e sua mãe.

Vale assinalar que, diferentemente do processo de autoconstrução narrado amplamente pela literatura nos anos de 1970 e 1980 (Kowarick, 1979), não foram encontrados casos de ajuda mútua comunitária para a construção de edificações. Embora alguns entrevistados tenham afirmado que suas casas foram originalmente construídas dessa forma (parcial ou completamente), a grande maioria das descrições e todas as descrições de eventos mais recentes indicam contratações via mercado ou processos coletivos, mas não comunitários, de construção. Por processo coletivo entendo uma dinâmica que envolve um grupo relativamente pequeno e seleto de pessoas e é baseado em reciprocidade pessoal, diferentemente dos processos comunitários, que envolvem a participação de um grande número de pessoas e têm a identidade ou a solidariedade comunitárias como fundamento principal. Na maior parte dos casos encontrados pela pesquisa, a construção foi executada por apenas alguns indivíduos da família e amigos muito próximos, havendo pagamento 
para parte das pessoas, em especial os que executaram serviços mais especializados (instalações elétricas e hidráulicas). Quase na totalidade das vezes esses serviços foram comprados no mercado por preços locais, de forma impessoal. Os casos de Jorge, Lúcia e Rafaela ilustram tal prática. Jorge, uma liderança comunitária em Paraisópolis, teve ajuda só do tio da esposa e do cunhado ao construir a casa, mas teve que pagá-los. Lúcia também só obteve ajuda de cunhados e do filho e Rafaela só do marido e de irmãos para a construção do barraco de madeira, ambos em Vila Nova Esperança. Atualmente, Rafaela vendeu se barraco para a irmã e hoje mora em uma casa de alvenaria comprada com suas economias de empregada doméstica.

Uma das regularidades mais presentes no conjunto dos resultados diz respeito a ajudas na migração, acolhendo pessoas e ajudando na obtenção do primeiro emprego na cidade. Por vezes quem recepciona o migrante recente, normalmente alguém da família ou amigo próximo do local de origem, chega a pagar os custos da viagem, com a combinação de receber o dinheiro de volta ou não. Algumas pessoas se especializam nesse tipo de ajuda. Lúcia, de Vila Nova Esperança, contou que seu cunhado recebe regularmente migrantes recém-chegados no bairro João XXIII, tanto de forma gratuita, como remunerada, chegando a construir pequenas unidades habitacionais no fundo do seu lote para alugar. Outras pessoas não cobram por este tipo de auxílio, como a tia de Rafaela, de Vila Nova Esperança, que, além de recebê-la, alojou muitas outras pessoas da família. A casa dela "parecia um albergue", diz a jovem.

Nos relatos são também relativamente comuns as migrações pendulares, como nos casos de Luciano, do Jaguaré, José, dos cortiços, e Rafaela, de Vila Nova Esperança, que migraram várias vezes entre São Paulo e suas cidades natais. Além desses casos, vários entrevistados contaram histórias de migrações de retorno. José, dos cortiços, e João, de Tiradentes, por exemplo, relataram a existência de parentes que vieram, não se adaptaram e voltaram. Nas palavras de João, eles "não se adaptaram porque do Nordeste para cá parece outro país. É muito diferente”.

Também foram encontrados casos de mudança de migrantes no interior da cidade, utilizando muitas vezes indivíduos de sua rede que moram em outros bairros. Essas mudanças são motivadas por conflitos com membros da família que os acolheu, ou pela busca de uma melhor inserção urbana e profissional. A primeira localização, entretanto, parece ser muito importante por estar associada às primeiras atividades profissionais, à formação de credenciais no mercado de trabalho urbano e à construção inicial da rede de relações de que disporão na cidade.

Por fim, ocorre a concessão de pequenos empréstimos de dinheiro que, no caso dos entrevistados, envolvem quantias entre $\mathrm{R} \$ 1,00$ e $\mathrm{R} \$ 10,00$. Na maior parte das vezes os empréstimos são obtidos com indivíduos da própria família ou amigos próximos, seja da vizinhança, seja do trabalho ou da igreja. Evidentemente, "a gente pede para quem sabe que pode", afirmou João, de Tiradentes. Trata-se, portanto, de pessoas próximas, mas com situação econômica um pouco melhor. Isso pode também causar um sentimento de vergonha. João, que é sozinho e não conta com apoio familiar, chegou a afirmar que já pediu a agiotas para não correr o risco de "receber um não de uma pessoa querida, aí eu ficava para morrer".

No caso dos comerciantes, esses pedidos parecem ser relativamente comuns, mas Luciano, do Jaguaré, afirmou que só empresta para "pais de família de boa índole e mães de família com famílias firmemente constituídas. Geralmente para pessoas de boa índole", envolvendo um filtro moral sobre o comportamento, caso contrário "o dinheiro pode ser usado para beber, jogar e alimentar vícios". Diversos entrevistados disseram que quem pede devolve sempre, mantendo assim a confiança e a possibilidade de apoio futuro. Para os comerciantes que emprestam, o motivo parece ser a manutenção das boas relações com a clientela, como afirma Luciano: "você tem aquela pessoa como seu cliente e não quer contrariar", mas também uma reciprocidade específica, pois "elas estão ali no diaa-dia ajudando", comprando coisas. Um importante elemento simbólico envolvido aqui parece ser a distinção e o respeito associados a quem empresta regularmente. Jorge, que é líder comunitário em Paraisópolis, além de comerciante, afirma que recuperar o dinheiro emprestado "varia muito de 
pessoa para pessoa. Tem gente que eu nem cobro". Nesse caso, trata-se de relações intrinsecamente assimétricas (e até mesmo hierárquicas em alguns casos), baseadas em uma reciprocidade em que a construção e a manutenção de prestígio ocupam posições de destaque.

Como esse tipo de ajuda envolve confiança e é personalizado, os indivíduos que o veiculam são de difícil substituição. Conseqüentemente, sua saída ou a redução do contato com elas (por aumento da distância física, dada a economia dos vínculos, ou rompimentos diversos) pode piorar as condições de apoio e gerar vulnerabilidade social (e, em situações extremas, até mesmo desfiliação social). Indivíduos migrantes recentes também tendem a se ressentir de sua baixa inserção local pela dificuldade de obter esse tipo de ajuda. As entrevistas sugerem que, entre os migrantes, essa é uma motivação importante para receber parentes. Para além do sempre citado desejo de melhora de vida para os parentes, como afirmou João, de Tiradentes: "trouxe porque vi e ainda vejo ainda muito progresso em São Paulo", a constituição de um núcleo familiar estendido fisicamente próximo pode trazer grande facilidade no cotidiano, além de conforto emocional, melhorando o acesso a esse tipo de auxílio e ao seguinte.

\section{Ajudas que envolvem confiança e intimidade}

Esse tipo de ajuda envolve empréstimos de alto valor, confidências e apoio emocional e político (para os indivíduos com vida política e associativa). Os vínculos que viabilizam essa ajuda dependem fortemente de confiança, e mesmo de intimidade. $\mathrm{Na}$ maior parte das vezes tal confiança envolve homofilia social, política ou mesmo moral.

Em alguns casos foram encontrados empréstimos de valor elevado, associados a entrevistados envolvidos com atividades comerciais. Os empréstimos nesses casos tinham sentido bastante mercantil, visto que apesar de não serem cobrados juros, estavam associados a compras de participação em sociedades. Entretanto, envolveram elementos evidentes de confiança, como é característico das relações de associação comercial, aumentados pelos diversos graus de informalidade característicos dessa esfera social, em que os vínculos da economia estão fortemente atravessados pela economia dos vínculos. Essa confiança é baseada em homofilia de comportamentos, como descrito por McPherson et al. (2001). O ego não empresta necessariamente para quem é próximo dele, mas para que tem comportamentos similares aos dele, considerados como confiáveis para os assuntos comerciais e de trabalho. Portanto, nesses casos freqüentemente não há intimidade na relação, envolvendo indivíduos que interagem apenas no domínio público.

Para as confidências e o apoio emocional em assuntos mais pessoais, entretanto, a situação é bastante diferente. No extremo, envolvem temas que Luciano, do Jaguaré, classificou como "picantes" ou momentos que Lucia, da Vila Nova Esperança, definiu como "hora da precisão". Nesses casos, a primeira dimensão de homofilia que aparece com força é a de sexo - mulheres confidenciam com mulheres e homens com homens. A exceção parece ser entre jovens que, em alguns casos, mantêm amigos confidentes de outro sexo. Entretanto, o caráter altamente seletivo desse tipo de apoio credencia apenas uma parte dos indivíduos, mesmo próximos, para veiculá-lo.

Outro requisito para o estabelecimento de relações baseadas em confidências parece estar associado à ausência de assimetria, e apenas em relações com baixa desigualdade esse tipo de ajuda pode ser prestado. Nesse sentido, a relação com alguns membros da família pode aparecer com sinal invertido, e a proximidade pode os descredenciar a se tornarem confidentes ou exercerem apoio emocional, embora isso por vezes não ocorra. Esse é o caso da relação entre pais e filhos de famílias com estrutura mais tradicional ou patriarcal, em que a gramática das relações envolve fortemente autoridade ou hierarquia. A presença de confidências entre mãe e filhas adolescentes ou adultas, no entanto, parece ser muito comum e um dos principais pontos de apoio emocional para ambas. Como já discutido, embora confiança possa estar presente em relações que envolvam autoridade, intimidade não está, sendo algo típico de relações entre iguais. Acredito que essa dimensão não é particular do grupo social analisado.

Um elemento adicional a destacar nas confidências e no apoio emocional diz respeito à homofilia 
de comportamentos, ou como afirmou João, de Tiradentes, quando "as idéias batem". Nas palavras de Luciano, do Jaguaré, "confiança para mim é a pessoa ter os mesmos hábitos que você, ela gostar das mesmas coisas que você, ela mostrar o mesmo caráter que você, freqüentar os mesmos ambientes que você e ter os mesmos gostos que você". Assim, é muito mais provável que indivíduos com crenças, comportamentos e práticas similares se tornem confidentes do que quando isso não ocorre. Os exemplos desse caso abundam, incluindo jovens que confidenciam a jovens com quem têm práticas comuns, homossexual que faz confidências com homossexuais, evangélicos que confidenciam a evangélicos, assim por diante. Essa seletividade parece estar ligada ao fato de que, como os assuntos são freqüentemente pessoais, envolvem julgamentos morais mediados pela existência de homofilia de comportamentos e idéias. Essa homofilia potencializa o compartilhamento de linguagens e repertórios que tornam mais fácil o entendimento das questões discutidas. ${ }^{13}$

Para os indivíduos que têm vida associativa, as entrevistas indicaram a existência de outro tipo de confiança específica - a política - , em que também está presente um tipo de homofilia de idéias relacionada com a similaridade de posicionamentos políticos. Por vezes, as relações são marcadas por um caráter hierárquico, como na relação entre um líder e membros de seu grupo político. Embora nessas relações possa existir confiança política, muito raramente aparecem confiança pessoal e intimidade, pois como David, um jovem de Paraisópolis, afirmou, "na questão política eu tenho certa dificuldade de colocar essas questões, pois para eles a gente tem que mostrar certa capacidade, certa força, e aí eu me sinto impossibilitado e não fico à vontade que eles conheçam fraquezas minhas". A gramática das relações hierárquicas é pouco compatível com a intimidade.

No caso das ajudas mais custosas e baseadas em confiança, a redução da presença de indivíduos mobilizáveis na rede de um dado ego pode criar problemas ainda mais dramáticos do que nas ajudas anteriores. Isso pode acontecer por deslocamento físico, mas também por quebra de confiança ou redução da intimidade, levando à redução do apoio, em especial o emocional. Em casos extremos, isso pode ocorrer mesmo nas relações familiares. É o caso de Cristina, uma jovem de 24 anos de Tiradentes, desempregada e mãe de três filhos. $\mathrm{Na}$ primeira entrevista a jovem morava com a família do marido. Um ano depois, havia sido agredida por ele, brigado com os sogros e morava na casa dos pais, com o terceiro filho. Os seus outros filhos, hoje com 11 e 9 anos (de outros pais), já eram criados por sua mãe, mas, nesse caso, não se tratava de ajuda com as crianças, mas de adoção (informal), perdendo a mãe o controle sobre os destinos das crianças.

Cristina alega que a sua família não tolera o marido, pai do terceiro filho. Ele não trabalha, freqüenta gangues e a maltrata fisicamente com freqüência. Toda vez que ela era agredida, seus irmãos batiam no marido, mas ela em seguida voltava com ele. Depois que esta situação se repetiu vezes, ela perdeu completamente o crédito com a família em termos morais, resultando em uma situação em que os vínculos ainda existem, mas os conteúdos esperados (por serem de família) foram esvaziados. Assim, apesar de morar hoje na casa dos pais, a entrevistada nem mesmo fala com a maior parte das pessoas da família, que a trata com visível desprezo. Para uma pessoa nessa situação, as relações que veiculam apoio emocional e ajudas baseadas em confiança estão praticamente exauridas; Cristina parecia estar às portas do desespero. Segundo seu relato, a única pessoa que continuava a ajudá-la era um morador do prédio que tinha pena dela (solidariedade difusa e despersonalizada). No entanto, a natureza das relações familiares é tão forte que a família a aloja e a alimenta.

O conteúdo de vínculos de uma determinada rede também pode aumentar a disponibilidade de indivíduos potencialmente associados a ajudas custosas e baseadas em confiança. Isso pode ocorrer inclusive como produto das próprias ajudas prestadas. Um caso reportado por Joana, que mora em um cortiço com dois filhos, ilustra essa situação. Sua vizinha, recém-chegada e sem conhecidos no cortiço, tinha três filhos pequenos e não tinha com quem deixá-los quando ia trabalhar. Como ela deixava os filhos trancados no quarto durante todo o dia, uma outra moradora denunciou a situação ao Conselho 
Tutelar da Infância, e a polícia apareceu para averiguar. Joana recolheu as crianças em seu quarto, escondendo-as da polícia, e afirmou que a denúncia era falsa. Desde esse dia, Joana e a vizinha são muito próximas e se ajudam reciprocamente, tendo se tornadas amigas íntimas.

\section{Conclusão}

Considerando a complexidade do padrão encontrado, sumarizo nesta conclusão as principais dimensões envolvidas. De uma forma geral, as informações sugeriram que as ajudas variavam segundo os custos envolvidos (materiais e imateriais) e a confiança necessária, entendida como segurança do cumprimento das expectativas da relação, quaisquer que sejam.

Em um extremo, localizam-se as ajudam pouco custosas e que podem ser veiculadas por relações de baixa confiança, baseadas em solidariedades difusas e impessoais. Esse grupo inclui ajuda como, por exemplo, acudir alguém em momentos de crises de saúde, empréstimo de ferramentas e de mantimentos, necessidade de olhar a casa durante a ausência dos donos, além do fornecimento de informações sobre serviços e empregos. Esse tipo de ajuda é veiculado tipicamente por relações freqüentes, mas pouco intensas, e que não necessitam de confiança elevada.

Em um conjunto intermediário estão ajudas personalizadas que envolvem custos ou esforços crônicos e constantes, ligadas por relações com alguma confiança. Nesse caso, são freqüentes os pagamentos, mesmo para pessoas próximas, como forma de reduzir os custos envolvidos. Como se trata de auxílio personalizado, as pessoas que prestam tais serviços dificilmente podem ser substituídas, sendo que indivíduos com baixa inserção social tendem a encontrar dificuldades de mobilizar esse tipo de ajuda, em um mecanismo circular de produção de desigualdades.

Por fim temos as ajudas de alto custo ou/e que envolvem alta confiança e são muito personalizadas. A questão mais importante aqui diz respeito a apoio, baseando-se, portanto, em confiança pessoal, profissional ou política. Como as relações capazes de viabilizar esse tipo de ajuda são relativamente raras, sua ausência pode representar um importante elemento de vulnerabilidade para os indivíduos.

Toda essa dinâmica guarda certa circularidade, e indivíduos com inserção social mais precária apresentam grandes dificuldades para mobilizar ajudas mais custosas, perpetuando as desigualdades sociais. Por outro lado, a concessão de ajudas importantes pode mudar o conteúdo das relações, aumentando a confiança e, conseqüentemente, habilitando a relação a veicular ajudas mais custosas e íntimas.

\section{Notas}

1 Devo a observação dessa dimensão e a sua formulação a discussões com Encá Moya e Valéria Macedo, a quem agradeço.

2 Relações homofílicas são relações entre pessoas de mesmo atributo.

3 Ou, tecnicamente, a apenas um passo do ego.

4 Essa decisão mostrou-se muito acertada, pois as redes encontradas na pesquisa variaram entre cinco e 148 nós.

5 O sentido de acaso aqui não diz respeito à aleatoriedade estatística, visto que a probabilidade de qualquer dos moradores da comunidade ter sido escolhido não é igual (para não dizer de outros locais de moradia de indivíduos em situação de pobreza) e os percursos não foram exaustivos no interior de cada local de estudo, nem se lançou mão de "pulos" sistemáticos para a escolha de entrevistados. Diferentemente da construção de uma amostra aleatória dos pobres (ou dos pobres nos locais estudados), o desenho da pesquisa combinou escolha intencional de locais com abordagem ao acaso de moradores nas ruas das comunidades.

6 Não disponho de espaço suficiente neste artigo para apresentar as técnicas empregadas. Mas, de forma resumida, os dados relacionais oriundos das entrevistas foram processados em matrizes de contigüidade, a partir das quais foram geradas medidas relacionais de centralidade, intermediação, alcance e distâncias, assim como das redes egocentradas no ego e relativas à estrutura das redes. Para maiores detalhes sobre os métodos empregados, ver Marques (no prelo), e para referências técnicas sobre redes, ver Wasseman e Faust (1994) e Hanneman e Riddle (2005).

7 Para uma caracterização dos entrevistados e uma discussão comparativa entre seus atributos e os do 
conjunto dos indivíduos das áreas estudadas, ver Marques (no prelo).

8 Considerando a complexidade do padrão de influência dos condicionantes, optei por não apresentá-los nesse artigo, sendo o leitor interessado remetido a Marques (no prelo).

9 Tilly (2005) constrói uma teoria a respeito da reprodução de desigualdades associadas a categorias socialmente construídas como pares opostos - homem/ mulher, branco/negro etc. Para ele, certos processos societários e organizacionais tornam a reprodução de tais desigualdades circular e cumulativa, o que explora seu caráter durável e resiliente.

10 O raciocínio, evidentemente, considera que as demais condições do mercado de trabalho sejam constantes e que as redes ligadas ao ego por vínculos fortes não mudem muito, caso contrário informação nova pode chegar pela transformação do ambiente econômico e das redes, independentemente da força dos vínculos.

11 Guimarães (2004) encontrou resultados compatíveis com essa interpretação ao aplicar um survey junto a demandantes de emprego em São Paulo. Embora sem estudar as redes diretamente, a autora indicou um decréscimo de importância relativa na busca de emprego dos círculos mais próximos dos indivíduos à medida que avança a idade.

12 Vale destacar o paralelismo desse raciocínio com a crítica de Karl Polanyi (1980) à idéia do livre mercado como campo das relações econômicas desencarnadas das relações sociais. Tanto o mercado como o Estado são partes constitutivas da sociedade, atravessados por vínculos de diversos tipos, e podem ser separados dela apenas analiticamente, e mesmo de forma provisória. A ontologia das relações entre o Estado e o seu entorno imediato (assim como do mercado), entretanto, não pode desconsiderar suas inserções mais amplas.

13 Renata Bichir chamou-me a atenção para essa dimensão, a quem agradeço.

\section{BIBLIOGRAFIA}

BLOKLAND, T. (2003), Urban bonds. Londres, Basil Blackwell.

CEM/SAS. (2004), Mapa da vulnerabilidade social da população da cidade de São Paulo. São Paulo, CEM/ Cebrap; SAS/PMSP; SESC.

FIGUEIREDO, A.; TORRES, H. \& BICHIR, R. (2006), "A conjuntura social brasileira revistada". Novos Estudos Cebrap, 75: 173-184.
FIGUEIREDO, A.; TORRES, H.; LIMONGI, F.; ARRETCHE, M. \& BICHIR, R. (2005), "Relatório final, Projeto BRA/04/052 - Rede de Pesquisa e Desenvolvimento de Políticas Públicas: REDE-IPEA II" (mimeo.).

GRANOVETTER, M. (1973), "The strength of weak ties". American Journal of Sociology. 78 (6): 1360-1380.

GUIMARÃES, N. (2004), “Transições ocupacionais e formas de desemprego em São Paulo e Paris". Trabalho apresentado no Seminário Estrutura Social e Segregação, São Paulo/Rio de Janeiro/Paris, CEM/Cebrap.

HANNEMAN, R. \& RIDDLE, M. (2005), Introduction to social network methods. Riverside, CA, University of California.

KOWARICK, L. (1979), A espoliação urbana. Rio de Janeiro, Paz e Terra.

LAMMONT, M. \& SMALL, M. (2008), “How culture matters for the understanding of poverty: enriching our understanding", in D. Harris e A. Lin, The colors of poverty, Nova York, Russell Sage Foundation.

LANNA, M. (1995), A dívida divina: troca e patronagem no Nordeste brasileiro. Campinas, Editora da Unicamp.

LIPSKY, M. (1980), Street-level bureaucracy: dilemmas of the individual in public services. Nova York, Russell Sage Foundation.

LOTTA, G. (2006), Saber e poder: agentes comunitários de saúde aproximando saberes locais e politicas públicas. São Paulo, dissertação de mestrado, Fundação Getúlio Vargas.

MARQUES, E. (2008), "Do social networks matter for poverty?". Artigo apresentado no Encontro Anual do Research Committee 21 da Internationbal Sociological Association (ISA) em Tóquio, Japão.

- (2009), "Como são as redes de indivíduos em situação de pobreza no Brasil urbano?". Artigo apresentado no Encontro da Associação Nacional de Pesquisa e Planejamento Urbano e Regional (Anpur) realizado em Florianópolis, Brasil.

MARQUES, E. (no prelo). Redes sociais, segregação e pobreza em São Paulo. São Paulo, Edusp.

MAUSS, M. ([1923] 2003), "Ensaio sobre a dádiva: 
forma e razão da troca em sociedades arcaicas", in $\longrightarrow$ Sociologia e antropologia, São Paulo, Cosac \& Naif.

MCPHERSON, M.; SMITH-LOVIN, L. \& COOK, J. (2001), "Birds of a feather: homophily in social networks". Annual Review of Socio$\log y, 27:$ 415-444.

NUNES, E. (1997), A gramática política do Brasil. Brasilia, Enap/Zahar.

POLANYI, K. (1980), A grande transformação. São Paulo, Campus.

TILLY, C. (2005), Identities, boundaries and social ties. Boulder, Paradigm.

VILELA, J. (2001), "A dívida e a diferença: reflexões a respeito da reciprocidade". Revista de $A n$ tropologia, 44 (1): 85-220.

WASSEMAN, S. \& FAUST, K. (1994), Social network analysis: methods and applications. Cambridge, Cambridge University Press.

WEBER, M. ([1922] 1999), Economia e sociedade: fundamentos da sociologia compreensiva. São Paulo, UnB/ Imprensa Oficial.

WELLMAN, B. (2001), The persistence and transformation of community: from neighborhood groups to social networks. Toronto. Consultado no site http:/ / www.chass.utoronto.ca/ $\sim$ wellman/publications/lawcomm/lawcomm7.PDF. 


\section{AS REDES IMPORTAM PARA O ACESSO A BENS E SERVIÇOS OBTIDOS FORA DE MERCADOS?}

\section{Eduardo C. L. Marques}

Palavras-chave: Pobreza; Sociabilidade; Redes sociais; São Paulo.

Este artigo discute o papel das redes sociais e da sociabilidade no acesso a bens e serviços obtidos por indivíduos pobres fora de mercados. São utilizadas informações qualitativas de uma pesquisa sobre redes de indivíduos pobres que habitam locais segregados em São Paulo, além de indivíduos de classe média utilizados como controle. Os resultados comprovam a importância das redes e sugerem que as ajudas que medeiam os acessos são dependentes dos tipos de relação e confiança envolvidos, assim como dos custos de ajudar. As dinâmicas observadas tendem a reiterar desigualdades, constituindo circularidades de reprodução da pobreza.

\section{DO SOCIAL NETWORKS MATTER FOR THE ACCESS TO GOODS AND SERVICES OBTAINED OUTSIDE MARKETS?}

\section{Eduardo C. L. Marques}

Keywords: Poverty; Sociability; Social networks; São Paulo.

This article discusses the role of social networks and sociability in the access by poor people to goods and services obtained outside of markets. The article uses qualitative information from a research about social networks of poor individuals living in segregated places in São Paulo, as well as middle class individuals used as a control. The results show the importance of networks and suggest that the helps that mediate the accesses depend upon the types of ties and trust involved, as well as the cost of helping. The observed processes tend to reiterate inequalities, establishing circularities of poverty reproduction.
EST-CE QUE LES RÉSEAUX IMPORTENT POUR L'ACCÈS AUX BIENS ET SERVICES OBTENUS EN DEHORS DES MARCHÉS?

\section{Eduardo C. L. Marques}

Mots-clés: Pauvreté; Sociabilité; Réseaux sociaux; São Paulo.

Cet article aborde le rôle des réseaux sociaux et de la sociabilité dans l'accès aux biens et services obtenus par des individus pauvres en dehors des marchés. Nous avons, pour cela, utilisé des informations qualitatives d'une recherche à propos des réseaux d'individus pauvres qui habitent des quartiers ségrégés à São Paulo, outre les individus de classe moyenne, utilisés comme contrôle. Les résultats confirment l'importance des réseaux et suggèrent que les aides qui assurent la médiation aux accès sont dépendantes des genres de relation et de la confiance qui sont engagés, ainsi que des coûts de cette aide. Les dynamiques observées tendent à réaffirmer les inégalités et constituent, de ce fait, des circularités de reproduction de la pauvreté. 